\title{
Polymer Inclusion Membranes with Strip Dispersion
}

\author{
Yueh-Hsien Li ${ }^{1}$, Da-Ming Wang ${ }^{1,2, *}$, Tzu-Yang Hsien ${ }^{3}$, Kuan-Ying Chan ${ }^{1}$ and Juin-Yih Lai ${ }^{2}$ \\ 1 Department of Chemical Engineering, National Taiwan University, Taipei 10617, Taiwan; \\ d01524004@ntu.edu.tw (Y.-H.L.); d03524003@ntu.edu.tw (K.-Y.C.) \\ 2 R\&D center for Membrane Technology, Chung Yuan University, Chung-Li 32023, Taiwan; jylai@cycu.edu.tw \\ 3 Center for General Education, China University of Technology, Taipei 11695, Taiwan; tyhsien@cute.edu.tw \\ * Correspondence: daming@ntu.edu.tw; Tel.: +886-2-3366-3006
}

Academic Editor: Stephen Gray

Received: 13 March 2017; Accepted: 28 May 2017; Published: 3 June 2017

\begin{abstract}
The present work investigated the permeation of indium ions through a polymer inclusion membrane (PIM), prepared with cellulose triacetate (CTA) as the base polymer, tris(2-butoxyethyl) phosphate (TBEP) as the plasticizer and di-(2-ethylhexyl)phosphoric acid (D2EHPA) as the extractant. With $5 \mathrm{M} \mathrm{HCl}$ aqueous solution as the strip solution, we observed an initial indium permeability of $2.4 \times 10^{-4} \mathrm{~m} / \mathrm{min}$. However, the permeability decreases with time, dropping to about $3.4 \times 10^{-5} \mathrm{~m} / \mathrm{min}$ after $200 \mathrm{~min}$ of operation. Evidence was obtained showing that hydrolysis of CTA occurred, causing a dramatic decrease in the feed $\mathrm{pH}$ (protons transported from strip to feed solutions) and a loss of extractant and plasticizer from the membrane, and then leading to the loss of indium permeability. To alleviate the problem of hydrolysis, we proposed an operation scheme called polymer inclusion membranes with strip dispersion: dispersing the strip solution in extractant-containing oil and then bringing the dispersion to contact with the polymer membrane. Since the strong acid was dispersed in oil, the membrane did not directly contact the strong acid at all times, and membrane hydrolysis was thus alleviated and the loss of indium permeability was effectively prevented. With the proposed scheme, a stable indium permeability of $2.5 \times 10^{-4} \mathrm{~m} / \mathrm{min}$ was obtained during the whole time period of the permeation experiment.
\end{abstract}

Keywords: polymer inclusion membranes; strip dispersion; indium; hydrolysis; stability

\section{Introduction}

Recovery and reuse of metal ions from industrial waste-streams can be of great help for environmental pollution control and for cost reduction. The liquid membrane process, a combination of ion extraction and stripping (back-extraction), has been widely studied for ion recovery and reuse [1]. For the process, extractant-containing oil is placed in between two aqueous solutions, the feed and strip solutions, and ion extraction and stripping thus occur simultaneously, ions being extracted from the feed to the oil and then being stripped from the oil to the strip solution. Because of its high selectivity for specific ions, the liquid membrane technique has attracted much research attention. However, large-scale applications of liquid-membrane processes are limited because of the difficulty in maintaining stable oil-water interfaces and in preventing extractant loss for long-term operations [2]. To improve the stability of liquid membrane, various operation schemes have been introduced [3]. One scheme that has been widely explored in recent years is the supported liquid membrane [4].

Supported liquid membrane (SLM) is an operation scheme that the extractant-containing oil is impregnated in the pores of a microporous hydrophobic membrane, which is placed in between the feed and strip solutions. Because of the water repellence of the hydrophobic membrane, the aqueous feed and strip solutions cannot penetrate into the membrane pores, and stable oil-water interfaces can thus form to allow for ion extraction and stripping. Though it is a promising scheme for practical 
applications, SLM still has a potential long-term stability problem of losing extractant-containing oil from the pores of the hydrophobic support [5]. Therefore, the SLM operation scheme has been modified for further improvement of long-term operation stability [6]. A promising technique under investigation is the SLM with strip dispersion [7] (SLMSD), in which the aqueous strip solution is dispersed in extractant-containing oil and then introduced to contact with the hydrophobic membrane. Though the oil can penetrate into the membrane pores, the strip solution cannot because the dispersed droplet of strip solution is much larger than the membrane's pores [7]. With this technique, the oil loss from the membrane pores to the feed can be greatly reduced by applying a pressure in the feed, and the extractant contained in the membrane pores can be replenished from the strip side in case it is lost to the feed due to its solubility in water or other reasons.

Another approach to improve the operation's stability is to replace the oil with a plasticized polymer membrane (gel). Since the extractant-containing phase in between the feed and strip solutions is not liquid, stability of oil-water interfaces does not need to be considered and the long term operational stability can thus be greatly improved. The technique is usually called polymer inclusion membranes (PIM): extractant and suitable plasticizer are entrapped in a base polymer to form the extractant-containing phase [8]. Studies were conducted to compare the transport fluxes and their long-term stabilities of SLM and PIM $[9,10]$. The results show that SLM had higher ion permeability while PIM had higher stability in cyclic and multi-hour operations. For practical applications, the enhancement of operation stability is usually worth a certain degree of permeability loss. However, the application of PIM is still limited because of the stability of the base polymer used [11]. The most commonly used base polymer for PIM is cellulose triacetate (CTA), which has good film-forming properties. However, a disadvantage of using CTA is its hydrolysis in acid and basic solutions. The concern of the long-term stability caused by CTA hydrolysis limits the practical application of PIM with CTA as the base polymer [12]. To resolve this problem, a typical approach is to use other base polymers for PIM [13]. In the present work, we propose another approach: change of the PIM operation scheme.

Presented in Figure 1a is a conventional operation scheme of PIM. The extractant-containing plasticized polymer membrane is placed in between the feed and strip solutions. With such a scheme, because the strip solution is usually highly acidic [14] or basic, the long-term operation would not be stable if the polymer membrane is not stable in highly acidic environment, such as being subject to hydrolysis. To alleviate the problem of material stability in strong acid or base, the present work adopted an operation scheme similar to SLMSD [7], dispersing the strip solution in extractant-containing oil and then bringing the dispersion to contact with the polymer membrane, as depicted in Figure 1b. For the new scheme, because the strip solution is dispersed in oil, it does not contact the strip solution at all times. The contact occurs only when the dispersed droplets reach the membrane surface. Since the contact time is greatly reduced, the long-term stability is improved. However, the introduction of the oil phase may have adverse effects, e.g., the ion transport may be slowed down by the extra mass transfer resistance caused by the oil phase (the ions stripped from the membrane need to transport through the oil and then to the dispersed strip solution; see Figure 1b). The operation scheme presented in Figure $1 \mathrm{~b}$ is called PIM with strip dispersion and abbreviated as PIMSD from now on. In the present work, experiments of recovery of indium ions were performed using both conventional PIM and PIMSD schemes, and the results were compared to evaluate the advantages and disadvantages of the proposed scheme. 


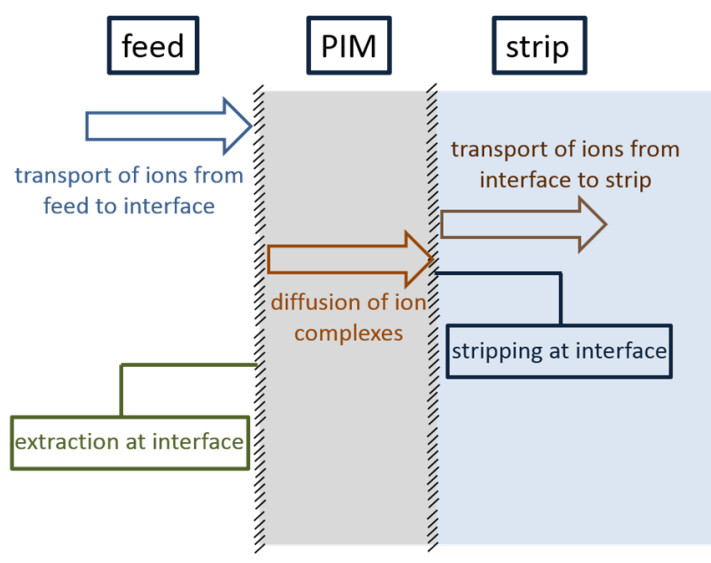

(a)

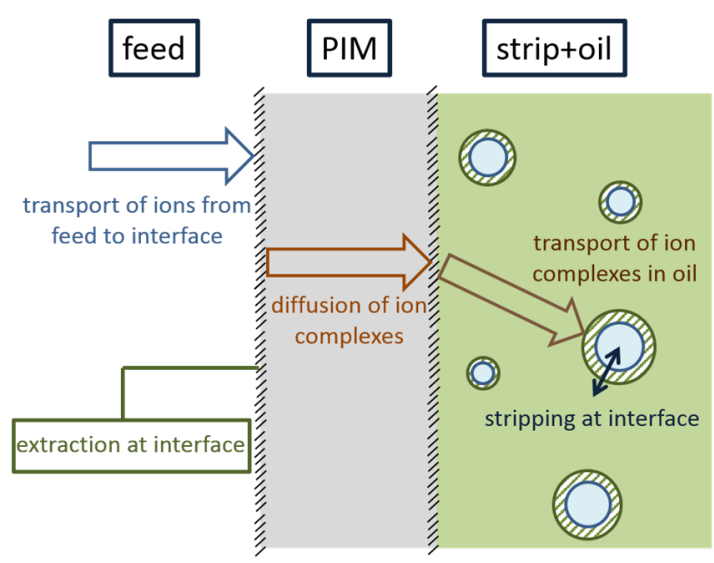

(b)

Figure 1. Schematic presentations of conventional PIM (a) and PIM with strip dispersion (b).

\section{Materials and Methods}

\subsection{Materials}

The polymer inclusion membranes used in the present work contained three major components: cellulose triacetate (CTA) (Mitsuhana, Kagiyama Iruma, Saitama, Japan) as the base polymer, tris(2-butoxyethyl) phosphate (TBEP) (Sigma-Aldrich, Shinagawa, Tokyo, Japan) as the plasticizer and di-(2-ethylhexyl)phosphoric acid (D2EHPA) (Merck, Hohenbrunn, Germany) as the extractant. Dichloromethane (Macron Chemicals, Phillipsburg, NJ, USA) was employed as the solvent to dissolve the three components. To examine the ion permeability of the prepared membranes, $\operatorname{In}\left(\mathrm{NO}_{3}\right)_{3}$ (Sigma-Aldrich, St. Louis, MO, USA) was dissolved in water to prepare the feed solution for permeation experiments and nitric acid (J.T. Baker, Phillipsburg, NJ, USA) was added to adjust solution $\mathrm{pH}$. Hydrochloric acid (Sigma-Aldrich, Wien, Austria) aqueous solution was used as the strip solution. For PIMSD, the strip solution was dispersed in the mixture of D2EHPA, 1-dodecanol (Acros, Geel, Belgium) and Isopar-L (ExxonMobil Chemical, Jurong Island, Singapore). All the reagents were used as received without further purification, and the water used was all de-ionized.

\subsection{Membrane Preparation}

PIMs were prepared by using the procedures reported in the literature [15]: $36.5 \mathrm{wt} \%$ of CTA, $27 \mathrm{wt} \%$ of TBEP and $36.5 \mathrm{wt} \%$ of D2EHPA were dissolved in dichloromethane to form homogeneous solution and the solution was cast on glass plates with a thickness of about $400 \mu \mathrm{m}$. The cast films were placed in the air overnight at room temperature to allow for the evaporation of dichloromethane. The formed membranes were then peeled off from the glass plates. The thickness at different positions (at least three points) of the membrane sample was measured by using a thickness gauge (Teclock, SM-1201, Nagano, Japan) and the membrane average thickness was $40 \pm 6 \mu \mathrm{m}$.

\subsection{Permeation Experiments}

Experiments of ion permeation through the prepared membranes were conducted at room temperature by using an apparatus composed of two cells, as schematically depicted in Figure 2a,b. The volume of each cell was $270 \mathrm{~mL}$; one is called the feed cell and the other the strip cell. Clamped in between the two cells was a membrane with circular shape of a diameter of $5.5 \mathrm{~cm}$. To perform conventional PIM permeation experiments, the feed solution containing about 20 ppm of indium ions $(\mathrm{pH}=1)$ was placed in the feed cell, and $\mathrm{HCl}$ aqueous solution $(1 \mathrm{M}, 2 \mathrm{M}$ or $5 \mathrm{M})$ was in the strip cell. Indium ions then permeated from the feed cell to the strip cell through the clamped membrane in between, as described in Figure 2a. For PIMSD, solution in the feed cell was the same as that for 
the conventional PIM, but placed in the strip cell was a liquid prepared by dispersing $\mathrm{HCl}$ aqueous solution $(5 \mathrm{M})$ in a mixture of D2EHPA, Isopar-L and 1-dodecanol. The mixture contained $0.6 \mathrm{M}$ of D2EHPA in Isopar-L and 1-dodecanol, and the volume ratio of Isopar-L to 1-dodecanol was 98:2. The mixture was immiscible with water. To effectively disperse the $5 \mathrm{M} \mathrm{HCl}$ aqueous solution in the oily mixture, agitation in the strip cell was needed, as indicated in Figure $2 \mathrm{~b}$. The agitation speed was $300 \mathrm{rpm}$. Note that the volume ratio of the strip solution to the feed was fixed at 1:27.

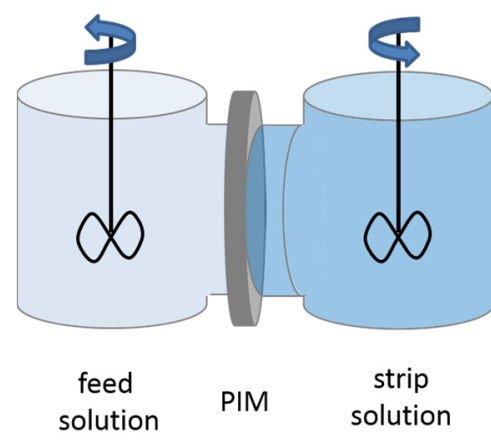

(a)

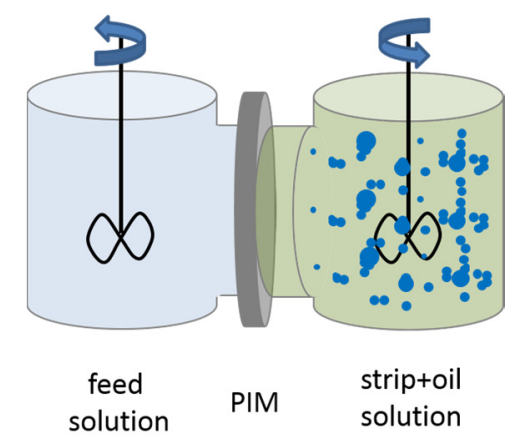

(b)

Figure 2. Schematic drawing of the two-cell setup for conventional PIM (a) and PIM with strip dispersion (b).

During the permeation experiment, the indium concentrations in the feed and strip cells were measured by using an inductively coupled plasma optical emission spectrometer (ICP-OES, Optima 2100 DV, Perkin Elmer, Waltham, MA, USA). Calibration was conducted in the range of 0-10 ppm each time the ICP-OES was used. All the reported indium concentrations were the average of three measurements. Similarly, the indium concentration in the $\mathrm{HCl}$ aqueous solution taken from the strip cell was determined with ICP-OES. Note that, for PIMSD, to take samples from the strip cell, agitation was stopped to allow for the separation of aqueous solution and oily mixture into two layers, and samples were then taken from the lower layer (density of the aqueous solution was greater). It took about $30 \mathrm{~s}$ for the dispersion to separate into two layers after ceasing agitation and a clear interface between the two phases was observed after the separation.

The time dependence of solution $\mathrm{pH}$ in the feed cell was also measured, by using a $\mathrm{pH}$ meter (Probe PHEF 012 SE, ProMinent, Heidelberg, Germany) with the detection pH-range from 0 to 12. The two-point calibration procedure was performed using standard buffer solutions $(\mathrm{pH}=7.00$ and 2.00). To examine the accuracy of the $\mathrm{pH}$ measurement, we used $1 \mathrm{M}$ and $0.1 \mathrm{M}$ hydrochloric acid standard solution (purchased by Fluka, Seelze (1 M), Steinheim (0.1 M), Germany) and a prepared $0.4 \mathrm{M}$ solution for testing. After equilibrium, the measured $\mathrm{pH}$ of the $0.1 \mathrm{M}$ standard was 1.02 (theoretical value 1.00), that for the $0.4 \mathrm{M}$ solution was 0.43 (theoretical value 0.40 ) and that for the $1 \mathrm{M}$ standard was 0.05 (theoretical value 0 ). The measured values were close to the theoretical ones.

\subsection{Membrane Characterization}

To investigate how membrane properties were changed during the permeation experiments, membranes were examined before and after the experiments by using Fourier transform infrared spectroscopy (FTIR) and scanning electron microscope (SEM). The IR spectra at $450-4000 \mathrm{~cm}^{-1}$ were obtained by using Perkin Elmer Spectrum 100 (Perkin Elmer, Waltham, MA, USA), with a resolution of $4 \mathrm{~cm}^{-1}$ and an average of 16 scans. To characterize the membrane morphology, membrane samples were fractured in liquid nitrogen and coated with platinum, and then were examined with SEM (Nova ${ }^{\mathrm{TM}}$ NanoSEM 230, FEI, Hillsboro, OR, USA).

The ratios of the phosphorous atoms contained at the surface of membrane samples were also examined by using X-ray photoelectron spectroscopy (XPS, Thermo Scientific, East Grinstead, UK). 
XPS spectra (survey scans) were acquired using K-alpha XPS with monochromatic Al K-alpha X-rays (beam energy $=1486.6 \mathrm{eV}$ ). The beam was incident normal to the specimen surface, and its size was $400 \mu \mathrm{m}$ in diameter. The X-ray source was operated at $210 \mathrm{~W}$, and the system operating pressure was $2 \times 10^{-8}$ Torr. The energy of emitted electrons was measured using a hemispherical energy analyzer with a pass energy $200 \mathrm{eV}$ (for survey). Data were collected at a photoelectron take-off angle of $90^{\circ}$ with respect to the sample surface. The ratio of phosphorous atoms was indicative of the composition of extractant (D2EHPA) and plasticizer (TBEP) in the membrane samples, since only these two components contain phosphorous atoms.

\section{Results}

\subsection{Operation Stability of PIM}

We first examined the permeation of indium ions through the prepared membranes with the conventional PIM scheme. The indium concentration in the feed cell was measured at various times during the permeation experiment. The results are presented in Figure 3a. The indium concentration in the feed decreased with time, indicative of the removal of indium ions from the feed cell.

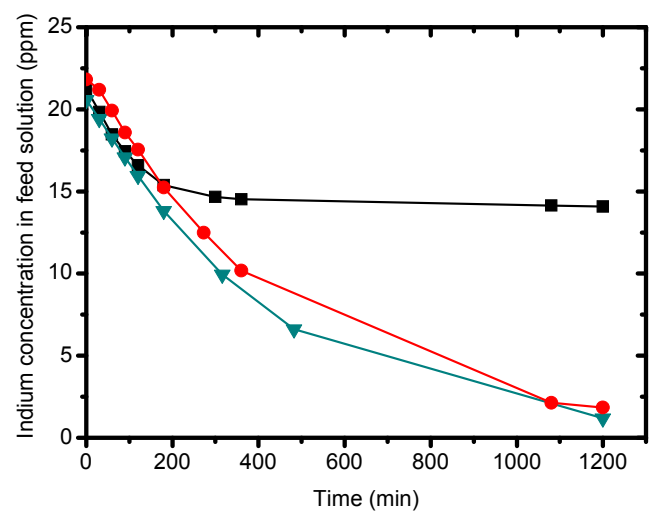

(a)

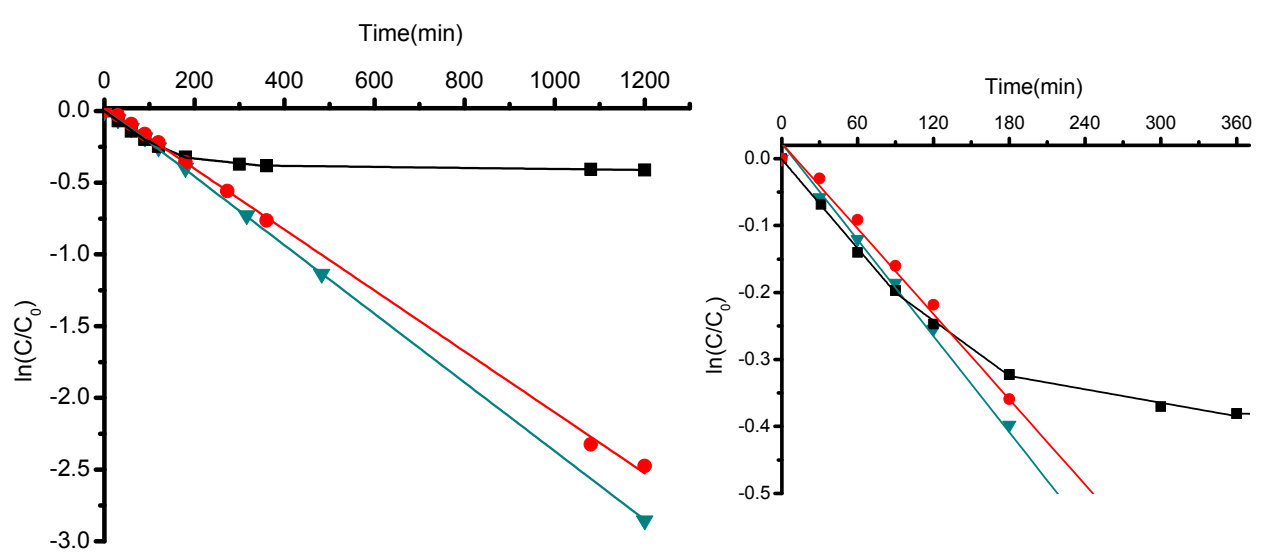

(b)

Figure 3. Time dependence of indium concentration in the feed solution for conventional PIM and PIMSD. (b) is the replot of the data of (a) in $\log$ scale, and the small figure in (b) is the magnification of the concentration change in the first $360 \mathrm{~min}$. $\mathbf{\nabla}$ : conventional PIM with $1 \mathrm{M} \mathrm{HCl}$ as the strip solution; - conventional PIM with $5 \mathrm{M} \mathrm{HCl}$ as the strip solution; $\bullet$ : PIMSD with $5 \mathrm{M} \mathrm{HCl}$ as the strip solution.

To characterize the indium permeability through the PIM, the following procedures were employed. With strong acidic solution as the strip solution, the ion concentration in the membrane at the interface between PIM and strip solution is close to 0 and the ion flux through the membrane $(J)$ 
can be described as $J=P \times C$, where $P$ is the ion permeability and $C$ represents the ion concentration in the feed. Performing mass balance on the feed cell and accepting the quasi-steady state assumption, one can obtain the equation for the time dependence of $C$ :

$$
\frac{\mathrm{d} C}{\mathrm{~d} t}=-\frac{A P C}{V}
$$

where $t$ denotes the time, $A$ represents the membrane area and $V$ the volume of feed cell. The solution to the above equation is $\ln \left(\frac{C}{C_{0}}\right)=-\frac{A P t}{V}$ where $C_{0}$ represents the initial ion concentration in the feed cell. According to the solution, plotting $\ln \left(\frac{C}{C_{0}}\right)$ versus $t$ should give a straight line of which the slope is $-A P / V$. With the slope and the knowledge of the membrane area $(A)$ and the cell volume $(V)$, the membrane permeability $(P)$ can be obtained.

With a strip solution containing $1 \mathrm{M}$ of $\mathrm{HCl}$, the indium concentration decreased from about $20 \mathrm{ppm}$ to $1 \mathrm{ppm}$ with $20 \mathrm{~h}$ permeation time, as shown in Figure 3a. The data was replotted using $\ln \left(\frac{\mathrm{C}}{\mathrm{C}_{0}}\right)$ versus $t$ and the results are shown in Figure $3 \mathrm{~b}$. A straight line was obtained that covers the whole operation time of $20 \mathrm{~h}$. The slope of the line was obtained and the permeability of the membrane can then be calculated: $2.7 \times 10^{-4} \mathrm{~m} / \mathrm{min}$. The obtained indium permeability was similar to that reported in the literature [15]: $6.0 \times 10^{-4} \mathrm{~m} / \mathrm{min}$.

Though the above results show that the solution of $1 \mathrm{M} \mathrm{HCl}$ can strip indium ions during the permeation experiment, strip solution with higher acidity is actually preferred for practical applications, because it can accommodate high amount of ions. For example, for recovery of indium ions by using the conventional extraction and stripping processes, the strip solution used was an aqueous solution with $5 \mathrm{M}$ of $\mathrm{HCl}$ [14]. We hence studied the indium permeation through PIM with a strip solution containing $5 \mathrm{M}$ of $\mathrm{HCl}$.

The time dependence of indium concentration in the feed for the case with $5 \mathrm{M} \mathrm{HCl}$ as the strip solution is also shown in Figure 3a. The two curves, for the conventional PIM operation scheme with strip solutions of $1 \mathrm{M}$ and $5 \mathrm{M} \mathrm{HCl}$, are close for the first $100 \mathrm{~min}$ permeation time. However, after $100 \mathrm{~min}$, the indium removal rate with $5 \mathrm{M} \mathrm{HCl}$ was lower than that with $1 \mathrm{M} \mathrm{HCl}$. After $300 \mathrm{~min}$, for the $5 \mathrm{M} \mathrm{HCl}$ case, almost no indium ions were removed from the feed cell and the indium concentration was kept at about $15 \mathrm{ppm}$. The decrease in indium permeability with permeation time for the $5 \mathrm{M} \mathrm{HCl}$ case can also be seen in Figure 3b. The initial slopes of the two lines, for the conventional PIM scheme with strip solutions of $1 \mathrm{M}$ and $5 \mathrm{M} \mathrm{HCl}$, are close, with corresponding permeabilities of $2.7 \times 10^{-4}$ and $2.4 \times 10^{-4} \mathrm{~m} / \mathrm{min}$. In Figure $3 \mathrm{~b}$, the slope of the curve for the case of $1 \mathrm{M} \mathrm{HCl}$ is almost constant throughout the whole permeation time range, making the curve a straight line, while the absolute value of the curve slope decreases with permeation time for the case of $5 \mathrm{M}$ $\mathrm{HCl}$. The results indicate that, during permeation, the ion permeability was constant for the $1 \mathrm{M}$ $\mathrm{HCl}$ case, but decreased with permeation time for the $5 \mathrm{M}$ case. With $5 \mathrm{M} \mathrm{HCl}$ as the strip solution, after about $200 \mathrm{~min}$ of permeation, the indium permeability was only about $1 / 10$ of the initial value.

\subsection{CTA Hydrolysis and the Stability of PIM}

The results discussed in the preceding section indicate that the membrane was not stable during the permeation experiment with the strip solution of $5 \mathrm{M} \mathrm{HCl}$. The base polymer was CTA, which is subject to hydrolysis in contact with strong acidic or basic solution. The decrease in membrane permeability might be caused by CTA hydrolysis.

We examined the morphology of the PIM surface in contact with the $5 \mathrm{M} \mathrm{HCl}$ strip solution before and after the permeation experiments. The SEM's are presented in Figure $4 \mathrm{a}, \mathrm{b}$. The membrane surface was smooth before its contact with the $5 \mathrm{M} \mathrm{HCl}$ solution and became rough after $20 \mathrm{~h}$ of contact. To investigate if the membrane deterioration was related to hydrolysis, we also performed FTIR analysis on the membrane before and after the permeation experiments. In Figure 5, the IR peak at around $1750 \mathrm{~cm}^{-1}$ corresponds to the $\mathrm{C}-\mathrm{O}-\mathrm{C}$ group and the peak at $3500 \mathrm{~cm}^{-1}$ is characteristic of 
the O-H group. Comparison of the spectra (a) and (b) in Figure 5 shows that, after the contact with $5 \mathrm{M} \mathrm{HCl}$ aqueous solution for $20 \mathrm{~h}$, the peak intensity of the membrane at $1750 \mathrm{~cm}^{-1}$ reduced, together with an increase in the intensity at $3500 \mathrm{~cm}^{-1}$, suggesting that the $\mathrm{C}-\mathrm{O}-\mathrm{C}$ group contained in CTA was converted to the $\mathrm{O}-\mathrm{H}$ group, indicative of the occurrence of hydrolysis reaction.

It has been reported in the literature [16] that hydrolysis of CTA could cause higher membrane permeability and lower selectivity for the CTA RO membranes. The reason was the enlargement of mean pore size. Such effect cannot explain our observation that the indium permeability decreased with permeation time with $5 \mathrm{M} \mathrm{HCl}$ as the strip solution (Figure $3 a, b$ ) since larger mean pore size should bring about higher permeability.

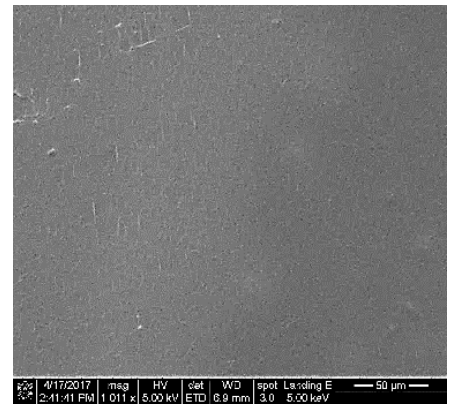

(a)

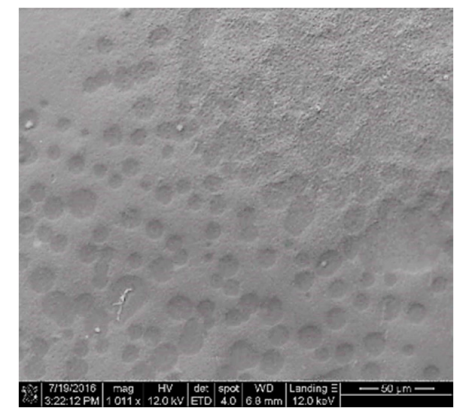

(b)

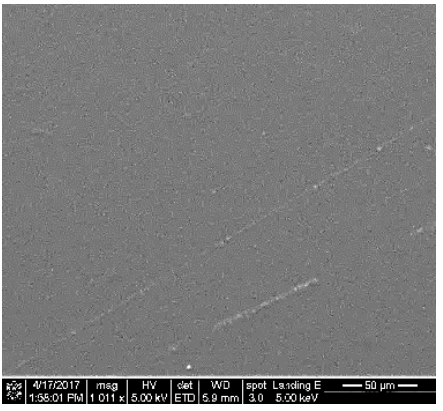

(c)

Figure 4. Morphologies of the membrane surfaces in contact with the liquid in the strip cell (a) before the permeation experiment; (b) conventional PIM scheme with $5 \mathrm{M} \mathrm{HCl}$ as the strip solution, after $20 \mathrm{~h}$ of permeation experiment; (c) PIMSD scheme with $5 \mathrm{M} \mathrm{HCl}$ as the strip solution, after $20 \mathrm{~h}$ of permeation experiment.

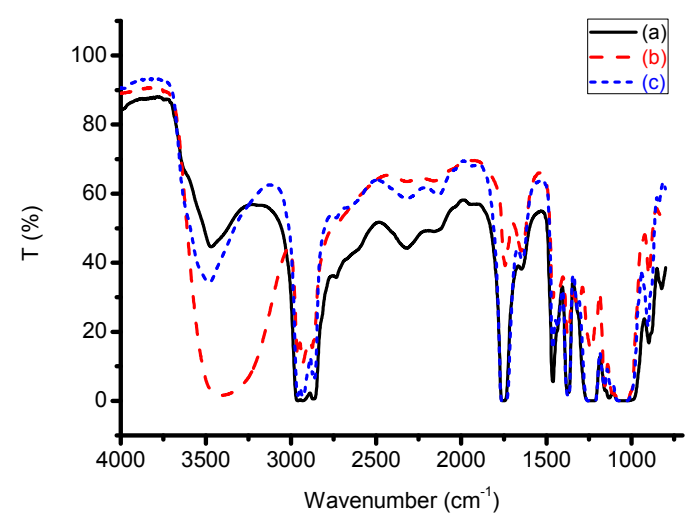

Figure 5. FTIR-spectra of the membranes before and after the contact with the liquid in the strip cell. (a) before the permeation experiment; (b) conventional PIM scheme with $5 \mathrm{M} \mathrm{HCl}$ as the strip solution, after $20 \mathrm{~h}$ of permeation experiment; (c) PIMSD scheme with $5 \mathrm{M} \mathrm{HCl}$ as the strip solution, after $20 \mathrm{~h}$ of permeation experiment.

We found that the loss of indium permeability was associated with an increase in proton permeability. We measured the solution $\mathrm{pH}$ in the feed cell and the results are presented in Figure 6 . With $1 \mathrm{M} \mathrm{HCl}$ as the strip solution, the $\mathrm{pH}$ in the feed was roughly constant during the $20 \mathrm{~h}$ of permeation. However, with $5 \mathrm{M} \mathrm{HCl}$ as the strip solution, we observed a dramatic decrease in $\mathrm{pH}$ during the permeation experiment, from 0.99 to 0.13 . The dramatic decrease in the feed $\mathrm{pH}$ during the permeation experiment would cause a decrease in the indium permeability of PIM. The extraction of indium ions by D2EHPA can be described by the following In-D2EHPA reaction $[17,18]$ :

$$
2 \mathrm{In}_{(\mathrm{aq})}^{+3}+5(\mathrm{HR})_{2(\mathrm{org})} \leftrightarrows \mathrm{In}_{2} \mathrm{R}_{10} \mathrm{H}_{4(\mathrm{org})}+6 \mathrm{H}_{(\mathrm{aq})}^{+}
$$


where HR represents the chemical formula of D2EHPA. According to the reaction, lower $\mathrm{pH}$ would favor the backward reaction (stripping) and hinder the forward reaction (extraction). The decrease in ion permeability of PIM with lower feed $\mathrm{pH}$ has been identified in the literature [19]. Therefore, it is reasonable to conclude that the decrease in feed solution $\mathrm{pH}$ played an important role in the decrease in indium permeability during the permeation experiment with $5 \mathrm{M} \mathrm{HCl}$ as the strip solution. The mechanism causing the enhancement of proton permeability is not yet clear. Part of the effects may come from the increase in the mean pore size of membranes due to hydrolysis, as discussed in the literature [20]. Another possible mechanism for the increase in proton permeability may be related to the enhancement of membrane hydrophilicity caused by hydrolysis. As shown in Figure 5, with $5 \mathrm{M} \mathrm{HCl}$ as the strip solution, hydrolysis converted the $\mathrm{C}-\mathrm{O}-\mathrm{C}$ group in CTA into the $\mathrm{O}-\mathrm{H}$ group. The conversion would make the membrane more hydrophilic, resulting in a higher degree of membrane swelling in aqueous solution. The higher degree of swelling would also enhance the proton permeability.

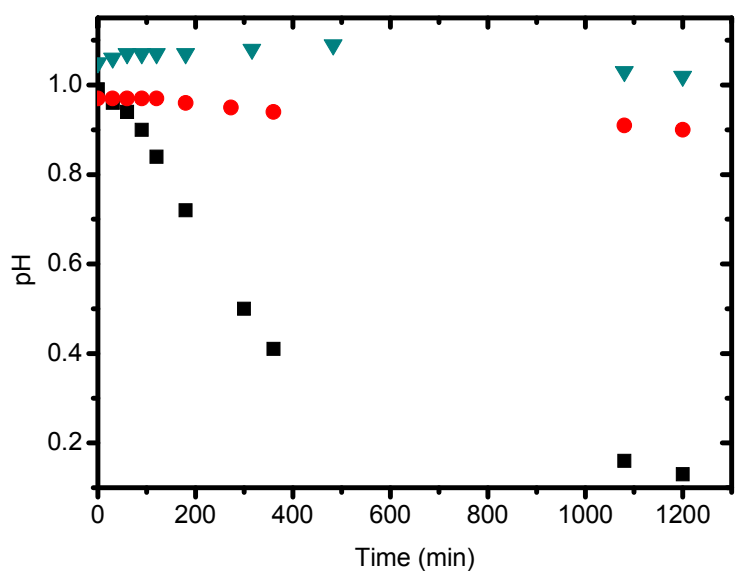

Figure 6. Time dependence of the solution $\mathrm{pH}$ in the feed cell. $\mathbf{\nabla}$ : conventional PIM with $1 \mathrm{M} \mathrm{HCl}$ as the strip solution; $\mathbf{n}$ : conventional PIM with $5 \mathrm{M} \mathrm{HCl}$ as the strip solution; $\bullet$ : PIMSD with $5 \mathrm{M} \mathrm{HCl}$ as the strip solution.

In addition to the increase in proton permeability, the contact with $5 \mathrm{M} \mathrm{HCl}$ solution caused loss of plasticizer and extractant molecules from the membrane. X-ray photoelectron spectroscopy was used to examine the content of carbon $(\mathrm{C})$, oxygen $(\mathrm{O})$ and phosphorous $(\mathrm{P})$ atoms at the membrane surface. The results are shown in Figure 7. The fraction of $\mathrm{P}$ atoms was $6.1 \mathrm{wt} \%$ before the permeation experiment and reduced to $2.0 \mathrm{wt} \%$ after the contact with $5 \mathrm{M} \mathrm{HCl}$ for $20 \mathrm{~h}$, indicating that TBEP and D2EHPA (the two components containing phosphorous atoms) were expelled from the membrane during the permeation experiment with $5 \mathrm{M} \mathrm{HCl}$ as the strip solution. The reduction of the content of plasticizer and extractant in the membrane can also play a role in the decrease in indium permeability. A possible mechanism responsible for the expelling of plasticizer and extractant is that the CTA became more hydrophilic due to the increased $\mathrm{OH}$ group caused by hydrolysis. The increase in hydrophilicity reduced the compatibility of CTA with the hydrophobic plasticizer (TBEP) and extractant (D2EHPA).

The results show that the enhancement of proton permeability and the reduction of the content of extractant and plasticizer played important roles in the loss of indium permeability during the permeation experiment. A possible mechanism was that the hydrolysis of CTA increased the $\mathrm{OH}$ groups contained in the membrane and made it more hydrophilic. The enhancement in membrane hydrophilicity made the membrane subject to higher swelling in aqueous solution, giving higher proton permeability, and lowered the compatibility between the base polymer (CTA) and the plasticizer (TBEP) and extractant (D2EHPA), causing lower indium permeability. The enlargement of membrane pores caused by CTA hydrolysis might also play a role in the increase in proton permeability. More investigation is still needed to get clear insight into the detailed mechanism. 


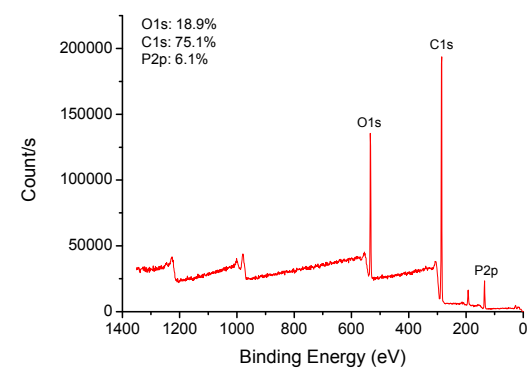

(a)

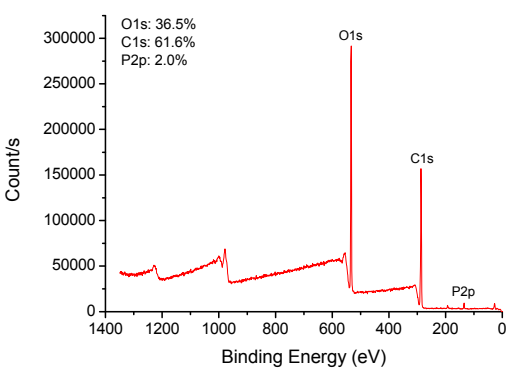

(b)

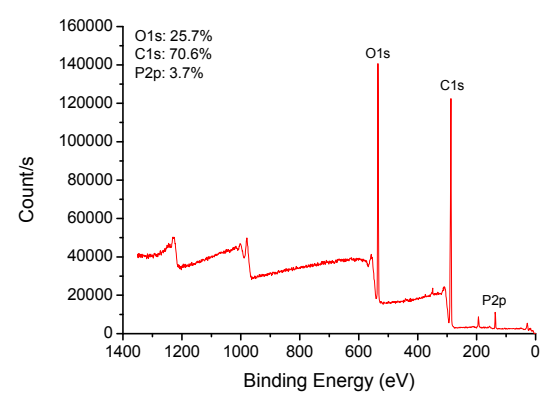

(c)

Figure 7. X-ray photoelectron spectroscopy survey results and the ratios of carbon, oxygen and phosphorous atoms (a) before the permeation experiment; (b) conventional PIM with $5 \mathrm{M} \mathrm{HCl}$ as the strip solution; (c) PIMSD with $5 \mathrm{M} \mathrm{HCl}$ as the strip solution.

\subsection{Polymer Inclusion Membranes with Strip Dispersion (PIMSD)}

In order to alleviate the hydrolysis of CTA caused by the contact of the membrane with the strong acidic strip solution, we dispersed the acidic strip solution in extractant-containing oil. The experimental set-up is shown in Figure 2b. Experiments of permeation of indium ions were performed and the time dependence of indium concentration in the feed cell is presented in Figure $3 a, b$. With the new scheme, even by using $5 \mathrm{M} \mathrm{HCl}$ aqueous solution as the strip solution, the decrease in membrane permeability during the permeation experiment was not observed and the indium permeability was kept constant during the operation: $2.4 \times 10^{-4} \mathrm{~m} / \mathrm{min}$.

The constant permeability during the permeation experiment, discussed in the preceding paragraph, indicates that the hydrolysis caused by the $5 \mathrm{M} \mathrm{HCl}$ was alleviated with the new operation scheme. We also examined the morphology of the membrane surface after $20 \mathrm{~h}$ of operation with the PIMSD scheme. As shown in Figure 4c, the membrane surface remained smooth with the new operation scheme. More direct evidence of the alleviation of hydrolysis can be seen from the FTIR analysis (Figure 5). The peak intensity of the $\mathrm{C}-\mathrm{O}-\mathrm{C}$ group $\left(1750 \mathrm{~cm}^{-1}\right)$ was higher and that of the $\mathrm{O}-\mathrm{H}$ group $\left(3500 \mathrm{~cm}^{-1}\right)$ was lower, compared with the conventional PIM scheme with $5 \mathrm{M} \mathrm{HCl}$ as the strip solution. The results indicate that the conversion of $\mathrm{C}-\mathrm{O}-\mathrm{C}$ group to $\mathrm{O}-\mathrm{H}$ group was greatly reduced by using the proposed scheme. Because hydrolysis was alleviated, the dramatic decrease in the feed $\mathrm{pH}$ was prevented (see Figure 6) and the loss of extractant and plasticizer during the permeation experiment was not as severe, evidenced by the $3.7 \mathrm{wt} \% \mathrm{of} \mathrm{P}$ (phosphorous atom) fraction remaining in the membrane after the permeation experiment ( $2.0 \mathrm{wt} \%$ remained with the conventional scheme).

The PIMSD scheme alleviated the CTA hydrolysis and thus enhanced the stability during the permeation experiment. However, the introduction of an extra oil phase might bring about extra mass transfer resistance, since the ions stripped from the membrane needed to be transported through the oil and then to the dispersed strip solution. To evaluate how the extra mass transfer resistance influenced the indium permeation, we compared the indium permeability through the membrane for the two operation schemes. With $5 \mathrm{M} \mathrm{HCl}$ as the strip solution, the indium permeability for the PIMSD scheme was almost the same as the initial indium permeability for the conventional PIM 
scheme. The results indicated that the introduction of the oil phase had little effect on the mass transfer resistance. A possible explanation is that the mass transfer resistance was mainly controlled by the resistance through the membrane, which was much greater than the extra resistance caused by the oil phase.

The agitation speed in the strip cell was $300 \mathrm{rpm}$ for the results discussed above. We also investigated the effect of agitation speed. The results show that the ion permeability was $2.4 \times$ $10^{-4} \mathrm{~m} / \mathrm{min}$ for $300 \mathrm{rpm}$ and $3.3 \times 10^{-4} \mathrm{~m} / \mathrm{min}$ for $450 \mathrm{rpm}$. With higher agitation speed, the ion permeability was higher. The reason we used $300 \mathrm{rpm}$ was because the membrane we prepared could not sustain $450 \mathrm{rpm}$ agitation speed for long. A thicker membrane or new design of the diffusion cell is needed to operate at an agitation speed of $450 \mathrm{rpm}$.

\subsection{Effect of the Acidity of Strip Solution on PIM Operation Stability}

We also examined the operation stability of the conventional PIM with $1 \mathrm{M} \mathrm{HCl}$ and $2 \mathrm{M} \mathrm{HCl}$ as the strip solution. Three operation runs were performed with a total operation time of $105 \mathrm{~h}$. With the data shown in Figure 8a,b, we calculated the ion permeability for the experiments with $1 \mathrm{M}$ and $2 \mathrm{M} \mathrm{HCl}$ as the strip solutions. For the three experimental runs with $2 \mathrm{M} \mathrm{HCl}$ as the strip solution, the decrease in permeability was seen clearly: decreasing from $2.5 \times 10^{-4} \mathrm{~m} / \mathrm{min}$ (1st run) to $1.8 \times 10^{-4} \mathrm{~m} / \mathrm{min}$ (2nd run), and then to $4.4 \times 10^{-6} \mathrm{~m} / \mathrm{min}$ (3rd run). Severe permeability loss was observed for the case of $2 \mathrm{M} \mathrm{HCl}$ after the first two runs (with a total operation time of $94 \mathrm{~h}$ ), though the loss was not as drastic as for the case of $5 \mathrm{M} \mathrm{HCl}$ (permeability loss occurred after about $200 \mathrm{~min}$ of operation (Figure 3)). For the case of $1 \mathrm{M} \mathrm{HCl}$, the ion permeability decreased from $2.3 \times 10^{-4} \mathrm{~m} / \mathrm{min}$ (1st run) to $1.8 \times 10^{-4} \mathrm{~m} / \mathrm{min}$ (2nd run), and then to $1.6 \times 10^{-4} \mathrm{~m} / \mathrm{min}$ (3rd run). Decrease in permeability was observed, but the loss was not severe. It should be noted that, for the case of $1 \mathrm{M} \mathrm{HCl}$, though the indium permeability loss was not severe during the operation time period we studied, proton transfer from the strip cell to the feed cell had occurred, as shown in Figure 9. As discussed in Section 3.2, the increase in the feed acidity was indicative of CTA hydrolysis. Therefore, it is expected that a drastic decrease in indium permeability would be observed with longer operation time. The results show that the conventional PIM scheme would not be stable for long operation, even with $1 \mathrm{M}$ or $2 \mathrm{M} \mathrm{HCl}$ as the strip solution. The PIMSD scheme proposed in the present work can help to make the operation more stable by alleviating the CTA hydrolysis.

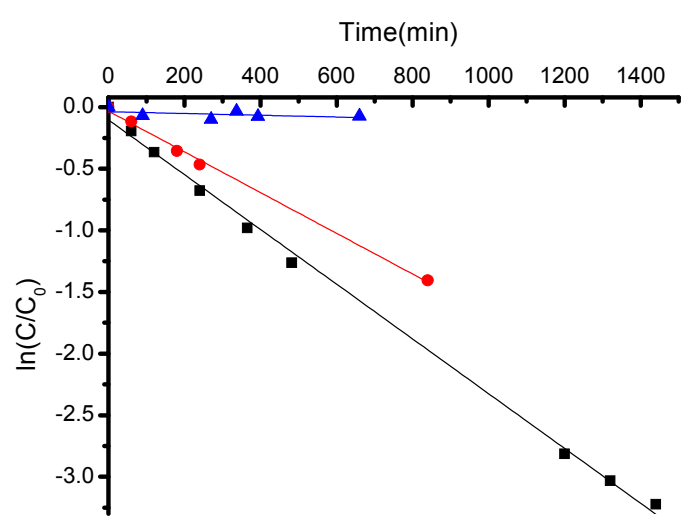

(a)

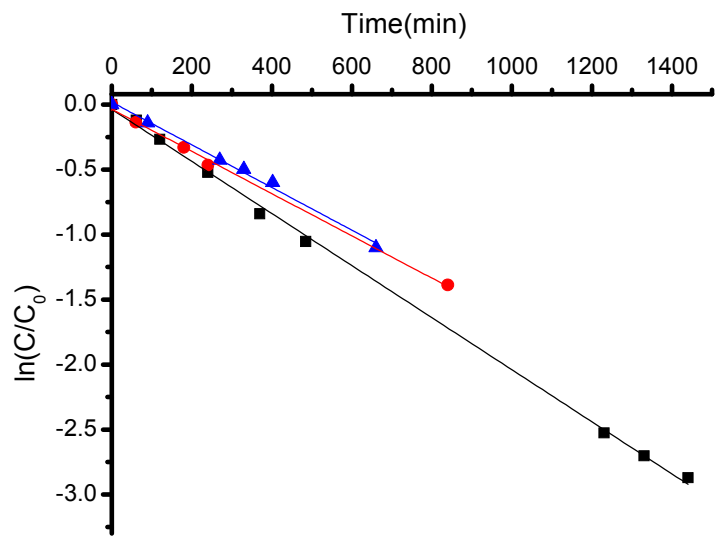

(b)

Figure 8. Time dependence of indium concentration in the feed solution. (a) conventional PIM with

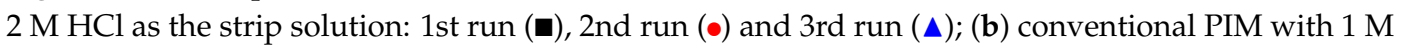
$\mathrm{HCl}$ as the strip solution: 1st run $(\mathbf{\square}), 2$ nd run $(\bullet)$ and 3 rd run $(\boldsymbol{\Delta})$. 


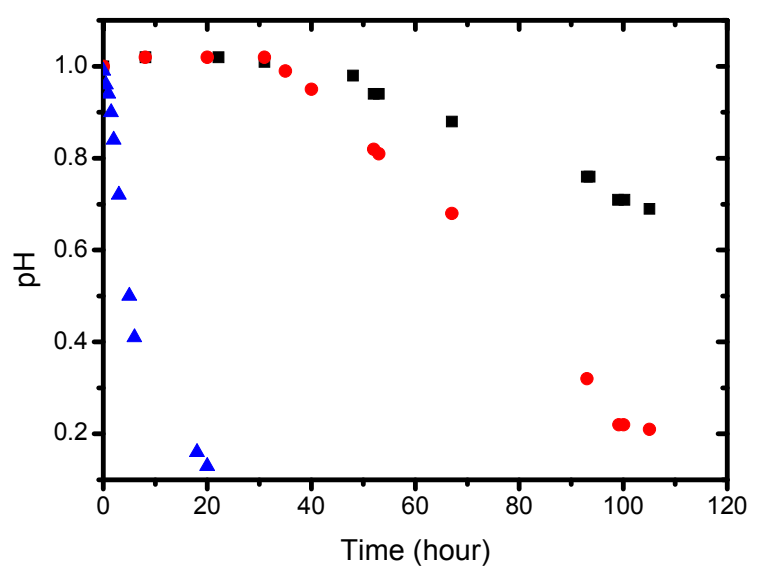

Figure 9. Time dependence of the solution $\mathrm{pH}$ in the feed cell. $\mathbf{a}$ : conventional PIM with $1 \mathrm{M} \mathrm{HCl}$ as the strip solution; $\bullet$ : conventional PIM with $2 \mathrm{M} \mathrm{HCl}$ as the strip solution; $\mathbf{\Delta}$ : conventional PIM with $5 \mathrm{M} \mathrm{HCl}$ as the strip solution.

\section{Conclusions}

For the conventional PIM operation scheme, the membrane was directly in contact with the strip solution. Because the strip solution is usually strong acid, the PIM operation would not be stable if the membrane material deteriorates in strong acid. For the present work, hydrolysis of CTA (membrane material) occurred with $5 \mathrm{M} \mathrm{HCl}$ as the strip solution, causing a dramatic decrease in indium permeability during the permeation experiment. The permeability loss can be effectively prevented by using the PIMSD operation scheme, with which the membrane did not directly contact the strong acidic strip solution, but contacted the dispersion of the strip solution in extractant-containing oil. Since the membrane did not contact the strong acid at all times, membrane hydrolysis was alleviated and the operational stability was maintained. With $1 \mathrm{M}$ or $2 \mathrm{M} \mathrm{HCl}$ as the strip solution, operational instability was still observed, although it was not as severe as that for the case of $5 \mathrm{M}$ $\mathrm{HCl}$. The PIMSD scheme proposed in the present work can make the PIM operation more stable by alleviating CTA hydrolysis.

Acknowledgments: The work was partially supported by the Ministry of Science and Technology, Taiwan (MOST 103-2221-E-002-248; MOST 104-2221-E-002-126).

Author Contributions: Yueh-Hsien Li: experimental design and performing; Da-Ming Wang: coordination of research ideas and experiments; Tzu-Yang Hsien: providing ideas for data analysis and material characterization; Kuan-Ying Chan: performing part of experiments; Juin-Yih Lai: providing ideas for experimental system design.

Conflicts of Interest: The authors declare no conflict of interest.

\section{References}

1. Marr, R.; Kopp, A. Liquid membrane technology—A survey of associated phenomena, transport mechanisms, and models. Chem. Ing. Tech. 1980, 52, 399-410. [CrossRef]

2. Yang, X.J.; Fane, A.G.; Soldenhoff, K. Comparison of liquid membrane processes for metal separations: Permeability, stability, and selectivity. Ind. Eng. Chem. Res. 2003, 42, 392-403. [CrossRef]

3. Sastre, A.M.; Kumar, A.; Shukla, J.P.; Singh, R.K. Improved techniques in liquid membrane separations: An overview. Sep. Purif. Methods 1998, 27, 213-298. [CrossRef]

4. Kocherginsky, N.M.; Yang, Q.; Seelam, L. Recent advances in supported liquid membrane technology. Sep. Purif. Technol. 2007, 53, 171-177. [CrossRef]

5. Kemperman, A.J.B.; Bargeman, D.; van den Boomgaard, T.; Strathmann, H. Stability of supported liquid membranes: State of the art. Sep. Sci. Technol. 1996, 31, 2733-2762. [CrossRef]

6. De Gyves, J.; de San Miguel, E.R. Metal ion separations by supported liquid membranes. Ind. Eng. Chem. Res. 1999, 38, 2182-2202. [CrossRef] 
7. Ho, W.S.; Poddar, T.K. New membrane technology for removal and recovery of chromium from waste waters. Environ. Prog. 2001, 20, 44-52. [CrossRef]

8. Schow, A.J.; Peterson, R.T.; Lamb, J.D. Polymer inclusion membranes containing macrocyclic carriers for use in cation separations. J. Membr. Sci. 1996, 111, 291-295. [CrossRef]

9. Religa, P.; Rajewski, J.; Gierycz, P. Advantages and disadvantages of SLM and PIM systems used for Chromium(III) separation from aqueous solutions. Pol. J. Environ. Stud. 2015, 24, 1283-1290.

10. Tayeb, R.; Fontas, C.; Dhahbi, M.; Tingry, S.; Seta, P. Cd(II) transport across supported liquid membranes (SLM) and polymeric plasticized membranes (PPM) mediated by Lasalocid A. Sep. Purif. Technol. 2005, 42, 189-193. [CrossRef]

11. Nghiem, L.D.; Mornane, P.; Potter, I.D.; Perera, J.M.; Cattrall, R.W.; Kolev, S.D. Extraction and transport of metal ions and small organic compounds using polymer inclusion membranes (PIMs). J. Membr. Sci. 2006, 281, 7-41. [CrossRef]

12. Casadella, A.; Schaetzle, O.; Nijmeijer, K.; Loos, K. Polymer inclusion membranes (PIM) for the recovery of potassium in the presence of competitive cations. Polymers 2016. [CrossRef]

13. Guo, L.; Liu, Y.H.; Zhang, C.; Chen, J. Preparation of PVDF-based polymer inclusion membrane using ionic liquid plasticizer and Cyphos IL 104 carrier for Cr(VI) transport. J. Membr. Sci. 2011, 372, 314-321. [CrossRef]

14. Nishihama, S.; Hirai, T.; Komasawa, I. Separation and recovery of gallium and indium from simulated zinc refinery residue by liquid-liquid extraction. Ind. Eng. Chem. Res. 1999, 38, 1032-1039. [CrossRef]

15. De San Miguel, E.; Monroy-Barreto, M.; Aguilar, J.C.; Ocampo, A.L.; de Gyves, J. Structural effects on metal ion migration across polymer inclusion membranes: Dependence of membrane properties and transport profiles on the weight and volume fractions of the components. J. Membr. Sci. 2011, 379, 416-425. [CrossRef]

16. Kumano, A.; Matsui, Y.; Numata, K.; Fujiwara, N.; Iwahashi, H.; Nagai, M. Performance change formula of cellulose triacetate hollow fiber RO membranes due to oxidation and hydrolysis. Desalination 1994, 96, 451-457. [CrossRef]

17. Sato, T. Extraction of indium(III), lanthanum(III) and bismuth(III) from sulfuric-acid solutions by Di-(2-ethylhexyl)-phosphoric acid. J. Inorg. Nucl. Chem. 1975, 37, 1485-1488. [CrossRef]

18. Sato, T.; Sato, K. Liquid-liquid-extraction of indium(III) from aqueous acid-solutions by acid organophosphorus compounds. Hydrometallurgy 1992, 30, 367-383. [CrossRef]

19. Salazar-Alvarez, G.; Bautista-Flores, A.N.; de San Miguel, E.R.; Muhammed, M.; de Gyves, J. Transport characterisation of a PIM system used for the extraction of $\mathrm{Pb}(\mathrm{II})$ using D2EHPA as carrier. J. Membr. Sci. 2005, 250, 247-257. [CrossRef]

20. Combe, C.; Molis, E.; Lucas, P.; Riley, R.; Clark, M.M. The effect of CA membrane properties on adsorptive fouling by humic acid. J. Membr. Sci. 1999, 154, 73-87. [CrossRef] 